\title{
Rupture of non-communicating horn of a bicornuate uterus
}

\author{
Jagannath Mishra*, Subhashree Rout
}

Department of Obstetrics \& Gynaecology, S.C.B Medical College, Cuttack, Odisha, India

Received: 14 March 2015

Accepted: 19 April 2015

\section{*Correspondence:}

Dr. Jagannath Mishra,

E-mail: jagannathmishra05@gmail.com

Copyright: (C) the author(s), publisher and licensee Medip Academy. This is an open-access article distributed under the terms of the Creative Commons Attribution Non-Commercial License, which permits unrestricted non-commercial use, distribution, and reproduction in any medium, provided the original work is properly cited.

\begin{abstract}
A primigravida at 20 weeks GA was referred as a case of bleeding P/V with an USG report showing intra-uterine foetal demise. Accordingly we induce her with misoprostol followed by ethacrydine lactate but there was no progress. On repeat USG here we saw there was rupture of a horn of uterus with abortus free in peritoneal cavity. On laparotomy there was 1 litre of hemoperitoneum with abortus lying free inside. There was rupture of a noncommnicating horn of a bicornuate uterus which was excised and uterine wall repaired.
\end{abstract}

Keywords: Non-communicating horn, Bicornuate uterus

\section{INTRODUCTION}

Pregnancy in a rudimentary horn of a bicornuate uterus is rare. ${ }^{1}$ An incidence of 1 in $76000-140000$ pregnancies is reported in the literature. ${ }^{2}$ Rudimentary horn may be communicating or non-communicating with the uterine cavity. There is no communication between the two cavities in $75 \%$ to $90 \%$ of the cases and the incidence of pregnancy in non-communicating horn is high as $83 \%$ with incidence of uterine rupture observed in $90 \%{ }^{3}$ of cases mostly in second trimester as was observed in our case.

\section{CASE REPORT}

A 24-year-old primigravida came to labour room with c/o bleeding $\mathrm{p} / \mathrm{v}$ for last one day with an USG report showing an intrauterine missed abortion of average gestational age 18 weeks.

O/E Pallor-mild, PR-92/min, BP-114/70mmHg; P/A-soft, uterus 16-18weeks; P/V- cervix long and os closed.

Accordingly tablet misoprost $50 \mu \mathrm{g}$ was given in posterior fornix repeating the same dose every 4 hourly for 4doses planning to expel the abortus but there was no result. So we plan to give ethacrydine lactate extraamniotic instillation.

After 48 hours of ethacrydine lactate instillation still the abortus was not expelled, so suspecting any uterine anomaly we did another USG in our department which showed there was rupture of a horn of bicornuate uterus with abortus lying in abdominal cavity.

Accordingly we planned for laparotomy immediately.

On opening abdomen, there was hemoperitoneum of about $1.5 \mathrm{~L}$ of blood along with clots which was drained. There was rupture of left sided horn with a normal size uterus with bilateral tubes \& ovaries attached to the normal uterus (Figure 1).

The horn was non-communicating type which was excised completely and lateral wall of uterus repaired (Figure 2).

Abortus was lying free in abdominal cavity which was removed (Figure 3). 
Pt. received 2 units blood transfusion and discharged on $7^{\text {th }}$ post-op day.

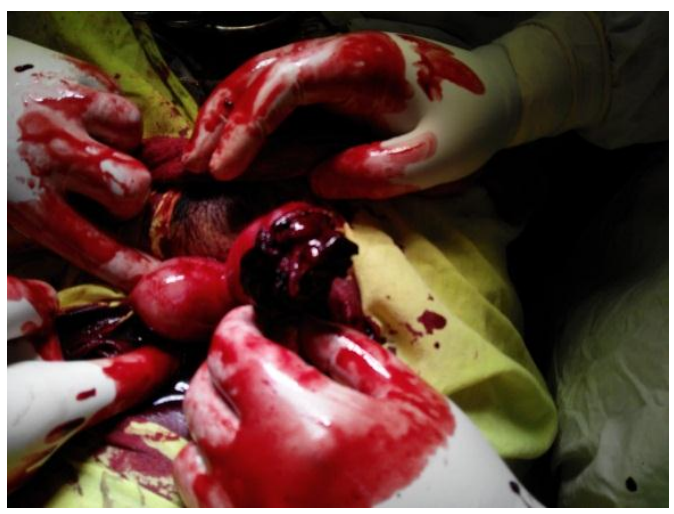

Figure 1: On opening abdomen, there was hemoperitoneum of about $1.5 \mathrm{~L}$ of blood along with clots which was drained.

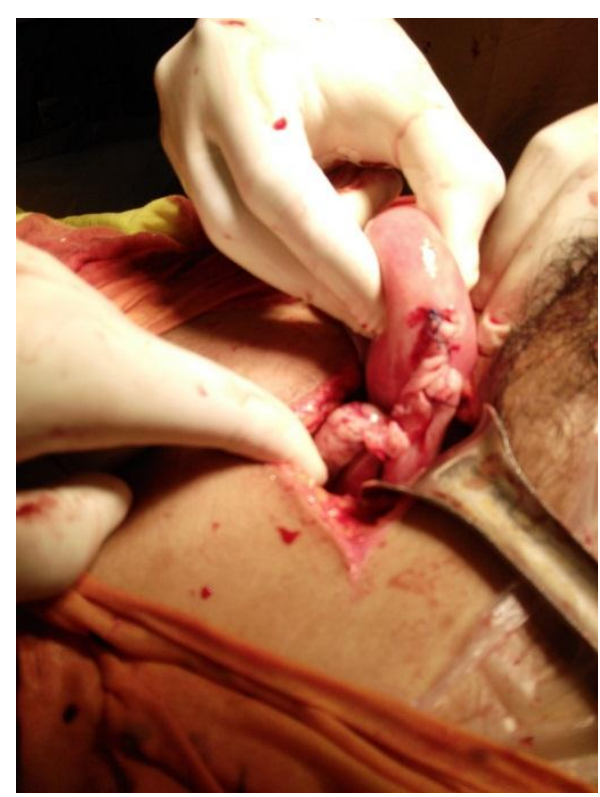

Figure 2: The horn was non-communicating type which was excised completely and lateral wall of uterus repaired.

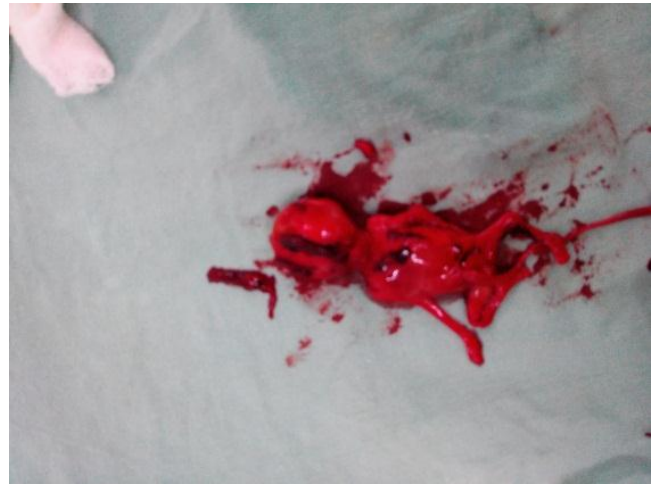

Figure 3: Abortus was lying free in abdominal cavity which was removed.

\section{DISCUSSION}

Any patient in the first and early second trimester of pregnancy who comes with missed abortion with a gestational age more than 12 weeks not responding to conventional methods for expulsion should be ruled out for uterine anomalies. High index of suspicion is the only thing which will prevail in the scenario of rising litigation.

Funding: No funding sources

Conflict of interest: None declared

Ethical approval: Not required

\section{REFERENCES}

1. Tufail A, Hashmi HA. Ruptured ectopic pregnancy in rudimentary horn of the uterus. J Coll Physicians Surg Pak. 2007;17(2):105-6.

2. Ural SH, Artal R. Third-trimester rudimentary horn pregnancy. A case report. J Reprod Med. 1998;43(10):919-21.

3. Goel P, Aggarwal A, Devi K, Takker N, Saha PK, Huria A. Unicornuate uterus with noncommunicating rudimentary horn - different clinical presentations. J Obstet Gynecol India. 2005;55(2):155-8.

DOI: 10.18203/2320-1770.ijrcog20150115

Cite this article as: Mishra J, Rout S. Rupture of non-communicating horn of a bicornuate uterus. Int $\mathrm{J}$ Reprod Contracept Obstet Gynecol 2015;4:873-4. 